\title{
Case Report and Review of the Literature
}

\section{Primary Leiomyosarcoma of the Lumbar Spine: A Case Report and Literature Review}

\author{
Eric Luis ${ }^{1 *}$, Vasanthie Balakrishnan ${ }^{1}$, Zairul KB ${ }^{2}$, Lim HS ${ }^{2}$, Khoh PS ${ }^{2}$, Marinah Aishah Bleasal ${ }^{1}$, Joey Ong ${ }^{1}$, Saw Le \\ Er $^{1}$ and Zulkiflee Osman ${ }^{2}$
}

${ }^{1}$ RUMC-Royal College of Surgeons of Ireland \& University College Dublin (Malaysia Campus), Penang, Malaysia ${ }^{2}$ PGH-Penang General Hospital, Malaysia

\begin{tabular}{l} 
A R T I C L E I N F O \\
\hline Article history: \\
Received: 8 December, 2020 \\
Accepted: 21 December, 2020 \\
Published: 14 January, 2021 \\
\hline Keywords: \\
Leiomyosarcoma \\
lumbar \\
spine \\
immunohistochemical staining \\
total en-bloc surgery
\end{tabular}
\begin{abstract}
A B S T R A C T
Primary vertebral leiomyosarcoma of the spine is extremely rare. Due to its rarity, the number of studies on pathology, treatment and prognosis is limited. Tissue Biopsy and Immunohistochemical staining techniques provide unequivocal diagnosis of leiomyosarcoma. The mainstay of treatment of spinal leiomyosarcoma is surgery, with or without radiotherapy and embolization. The principles of surgery comprise resection of tumor, decompression and stabilisation of the spinal cord and prevention of tumor recurrence. The Tomita total en-bloc resection is the preferred surgical technique. We hereby present a literature review of spinal leiomyosarcoma and a case report of the first case of a 56-year-old lady in Malaysia who was diagnosed with L3 vertebral leiomyosarcoma and lung metastasis.
\end{abstract}

(C) 2021 Eric Luis. Hosting by Science Repository.

\section{Introduction}

Leiomyosarcoma is one of the most aggressive soft tissue sarcomas, comprising approximately $7 \%$ of all soft tissue sarcomas [1, 2]. It typically originates from smooth muscle cells of the uterus, abdominal organs, retroperitoneum, and the extremities [3]. Primary leiomyosarcoma of the skeleton, especially of the spine, is very rare. Although Evans and Sanerkin in 1965 described first case of primary osseus leiomyosarcoma of the tibia, the femur is still by far the commonest site of osseous involvement [4-8]. The diagnosis of primary leiomyosarcoma of the spine requires the exclusion of the other possible causes of spinal metastasis from other primary sources. Tissue biopsy and immunostaining have remained the gold standard in establishing the diagnosis. The goals of management are:

\footnotetext{
i. Eradication of local primary spinal tumor;

ii. Control of local spinal and distant metastasis;

iii. Decompression of spinal cord and nerves;

iv. Stabilization of the of spinal column and;

v. Prevention of recurrence [9].
}

Bertil Stener in 1971 published the first case of a total spondylectomy (corpectomy), which involves the complete removal of the entire verterbra, in a case of chondrosarcoma of T6-T8 in a 49-year-old farmer [10]. Tomita subsequently in 1997 introduced Total en bloc spondylectomy (TES), which involves the removal of both the entire vertebral body and lamina as one compartment to minimize local recurrence $[11,12]$. While this technique allows total excision of tumor mass without tumor clell spillage and total removal of micro-lesions within the vertebra, it also allows total ligation of feeding vessels to avoid uncontrolled hemorrhage. Anterior column reconstruction can be achieved using an expandable cage, in conjunction with TES. The primary candidates for TES are primary malignant tumor (stage 1,2); aggressive benign tumor (stage 3 ); and isolated metastasis in a patient with long life expectancy [13, 14].

Chanplakorn et al. in 2011 reported a case using TES to resect a recurrent epithelioid sarcoma in the thoracic spine of a 14-year-old boy in Thailand [15]. In this report, we present the first case of primary L3 vertebral leiomyosarcoma with lung in Malaysia, treated with a 2-stage anterior corpectomy with expandable cage and posterior decompression and stabilization with posterior instrumentation.

${ }^{*}$ Correspondence to: Eric Luis, RUMC-Royal College of Surgeons of Ireland \& University College Dublin (Malaysia Campus), Penang, Malaysia; E-mail: G001@ntu.edu.sg,eric.luis@rcsiucd.edu.my

(C) 2021 Eric Luis. This is an open-access article distributed under the terms of the Creative Commons Attribution License, which permits unrestricted use, distribution, and reproduction in any medium, provided the original author and source are credited. Hosting by Science Repository. http://dx.doi.org/10.31487/j.SCR.2021.01.02 


\section{Case Presentation}

A 56-year-old Malay lady presented to the District General Hospital with progressively worsening low back pain over the past 5 months that was aggravated by movement and is relieved by rest. She had walked normally initially but required wheelchair ambulation 2 months later when low back pain became persistent. She is obese (BMI $37 \mathrm{~kg} / \mathrm{m} 2$ ) and suffers from hypertension and congestive cardiac failure. She underwent myomectomy a year ago and sustained a serious motor vehicle accident 23 years ago but recovered uneventfully. Clinical examination revealed bilateral motor weakness in lower extremities with power of grade 2/5 in L2 and L3 myotomes bilaterally, grade 3/5 in L4 myotomes bilaterally, grade $4 / 5$ in L5 myotomes bilaterally and full power in S1 myotomes bilaterally. Sensory modalities were reduced in the right L3 dermatome only, knee and ankle reflexes (-), Babinski (-) and clonus (-). Upper limb neurological assessment was normal. X-ray of the lumbar spine showed vertebra plana due to pathological compression fracture of L3. Flexion and extension views did not show any translational instability, as seen in (Figures 1A \& 1B). Chest X-ray showed suspicious nodules in both lung fields (Figure 1C).
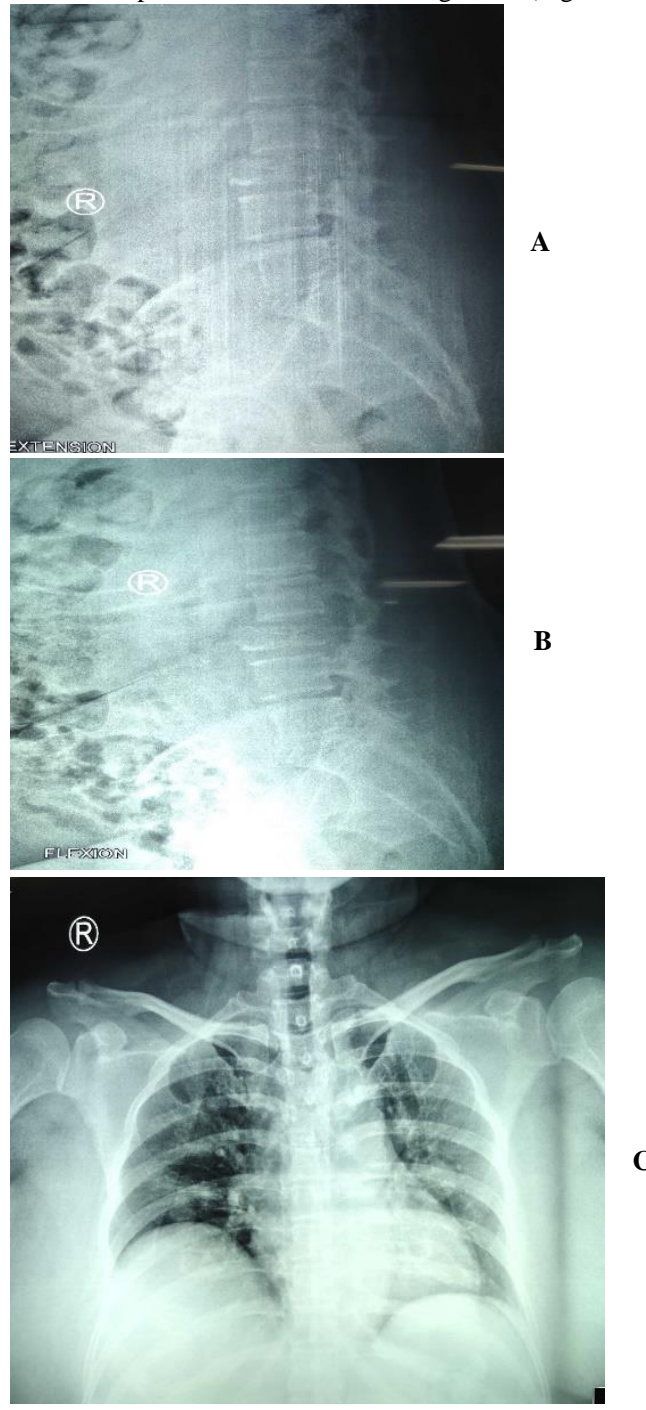

Figure 1: A) lateral view of $X$ ray of the spine in flexion. B) lateral view of $\mathrm{X}$ ray of the spine in extension. C) Chest $\mathrm{X}$ ray of the patient in AP view.
MRI of the lumbosacral spine revealed a mass of hypo T1/ intense T2/ intense STIR with lobulated margin in L3 which retropulsed posteriorly causing severe central and lateral canal stenosis of L3/L4. There was also a right paravertebral extension of the mass abutting the right psoas and into the right pedicle of L3 (Figure 2).

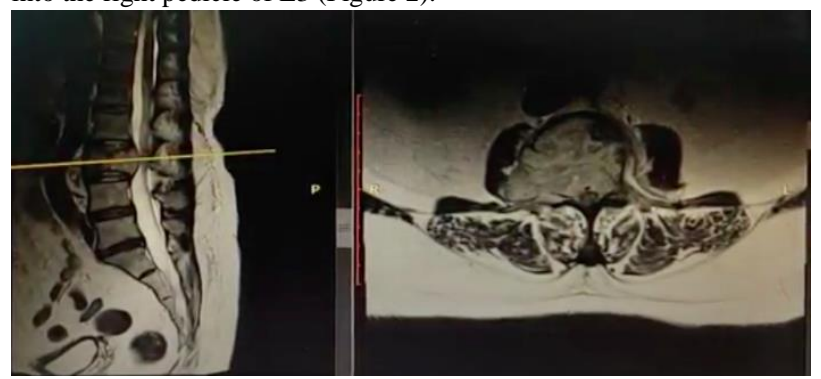

Figure 2: MRI showing a mass in the body and pedicle of L3 with associated right paravertebral expansion and protrusion into the right exiting and central canal of L3.

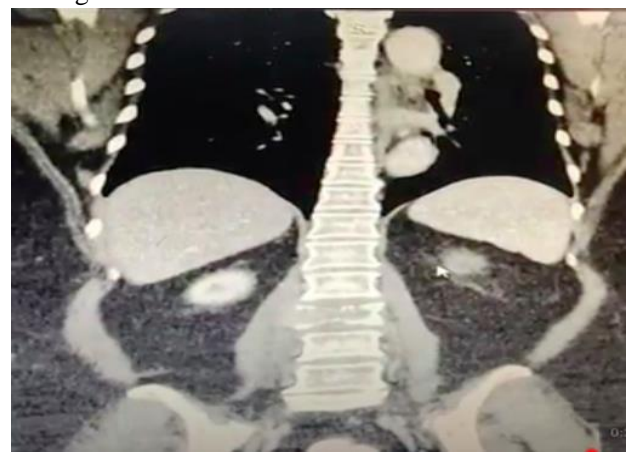

Figure 3: CT-TAP showing lung nodule in the right lateral segment.

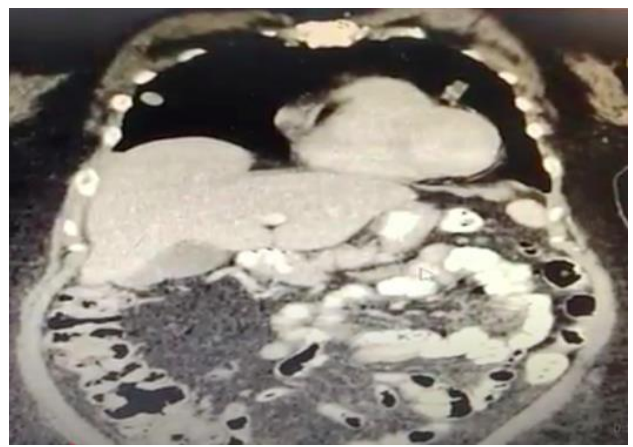

Figure 4: CT-TAP showing a destructive lytic and sclerotic bone lesion at L3 with soft tissue component causing severe central canal stenosis.

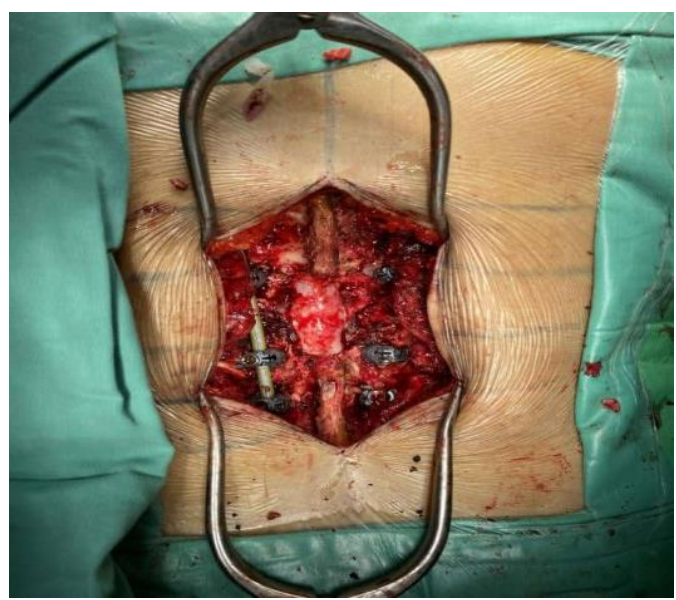

Figure 5: Posterior decompression, instrumentation, and stabilization. 
The CT scans of her thorax revealed two lung nodules in both the inferior lingular segment of left upper lobe $(1.67 \times 1.74 \mathrm{~cm})$ abutting the adjacent pericardium and lateral segment of right middle lobe $(1.31 \times 1.11 \mathrm{~cm})$ (Figures $3 \& 4$ ). The CT scans of her pelvis showed destructive lytic and sclerotic bone lesion was seen at L3 with soft tissue component causing severe central canal stenosis. She was then referred to Penang General Hospital (PGH) 4 months later for spinal decompression and posterior instrumentation and stabilization. On the third day of admission, the first stage surgery of posterior instrumentation L1 to 5 for decompression of L3 for pathological fracture was performed. (Figure 5). Intraoperatively, bilateral L3 pedicles were involved by tumor and were excised. The tumor tissue was found stuck down to the dura and encroaching on bilateral L2/L3 nerve roots (Figure 6).

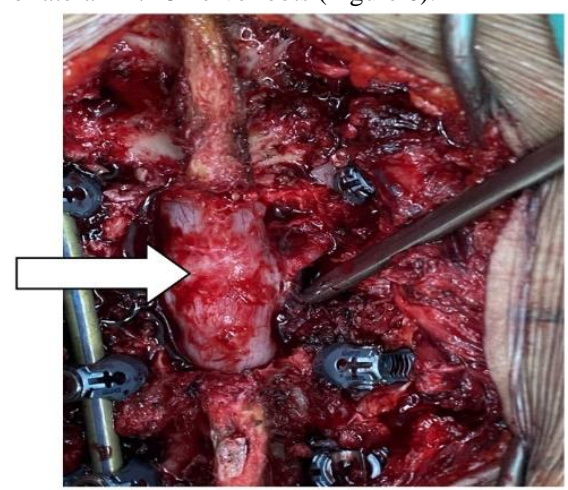

Figure 6: Tumor (red mass streaks) seen stuck down to the thecal sac (white) and encroaching nerve root and was inseparable from the dura.

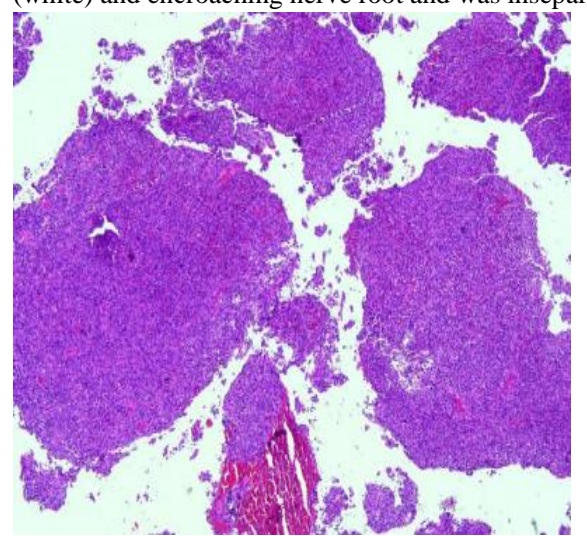

Figure 7: Tumor tissue arranged mainly in solid sheets and nests (40x magnification).

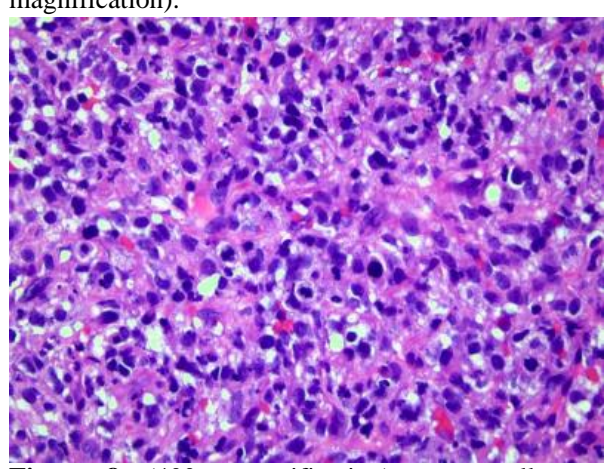

Figure 8: (400x magnification) tumor cells are of large mainly epithelioid, ovoid cells with occasional spindle cells. These cells exhibit hyperchromatic, moderately pleomorphic nuclei, some with prominent nucleoli. Mitosis are brisk.
The resected tumor was grossly greyish in colour, felt elastically hard, and had a sand-like appearance. The surgically resected tissue was sent to the department of pathology in our institution for histopathological examination. The hematoxylin and eosin (HE) staining and immunohistochemical staining with various antibodies against the epithelial and mesenchymal cell markers were performed to determine the identity of the tumor. H\&E show high grade malignant tumor that are mainly arranged in sheets, nests with focal vague fascicular pattern with many capillary networks. These cells are of large mainly epithelioid, ovoid cells with occasional spindle malignant cells. These malignant cells display hyperchromatic moderately pleomorphic nuclei, some with prominent nucleoli with elongated eosinophilic cytoplasmic processes with ill-defined borders. Mitosis are easily seen up to 60/10 h.p.f with abnormal forms (Figures 7 \& 8). Microbiological and $M$. tuberculosis culture and sensitivity screenings were all negative for both bone and soft tissue specimens.

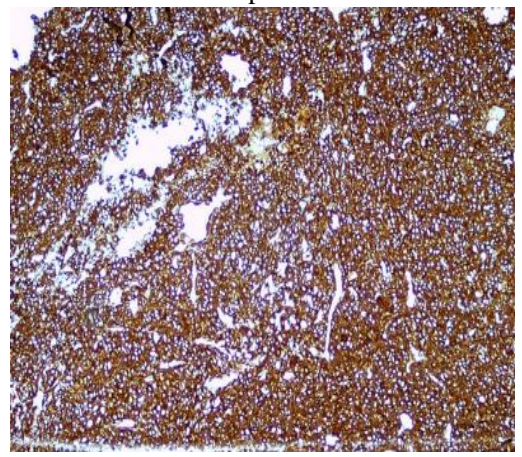

Figure 9: SMA immunostain positive.
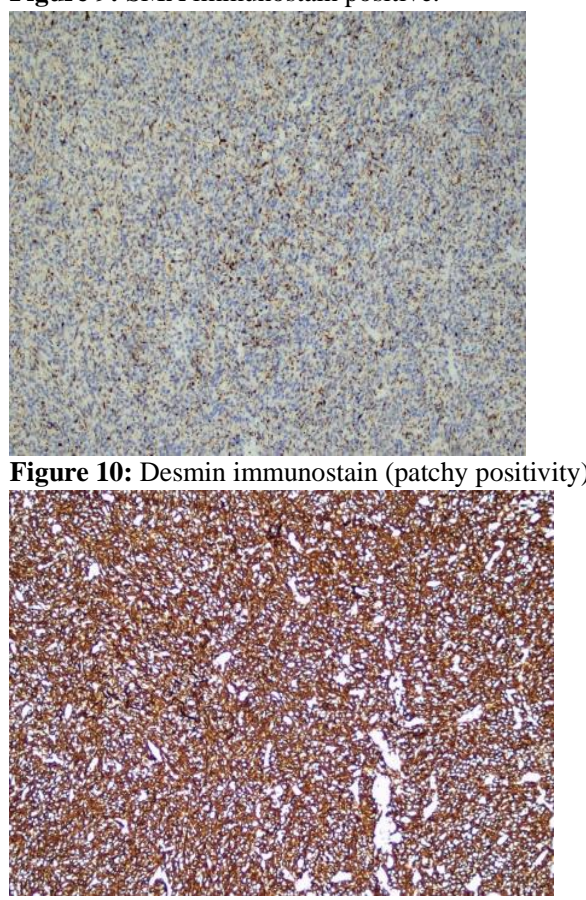

Figure 11: $\mathrm{H}$ caldesmon immunostain positive.

Immunohistochemistry stains showed the malignant cells are diffuse and strongly positive for SMA and h-caldesmon with patchy positivity towards desmin (Figures 9-11). They are negative for CKAE1/AE3, EMA, S100 protein and CD34. In conclusion, the histomorphology and immunohistochemical studies are highly suggestive of high grade epithelioid leiomyosarcoma FNCLCC Grade 3 (Score of 6). 


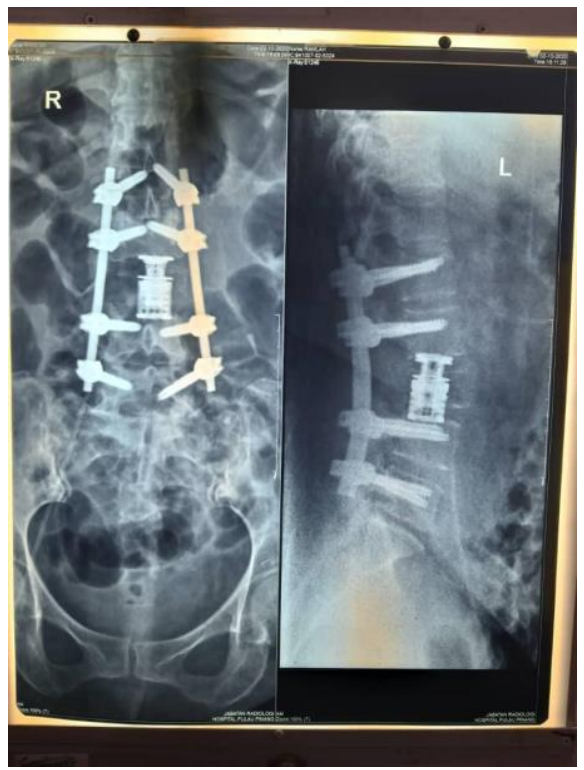

Figure 12: Anterior Corpectomy L3 and Reconstruction with expandable cage.

Post operatively, power in her lower limbs bilaterally improved from $2 / 5$ to $3 / 5$ for L2 myotomes bilaterally and L3 to $\mathrm{S} 1$ was restored to $5 / 5$ bilaterally; Sensory modalities were normal bilaterally. Two weeks postoperatively, the second stage of TES surgery was performed with anterior corpectomy of L3 and reconstruction with an expandable cage was performed. Post operatively lower limb power was $5 / 5$ bilaterally from L2 to S1 myotomes (Figure 12). She was subsequently arranged to receive adjuvant radiotherapy. The patient had an uneventful recovery and was discharged home one week later.

\section{Discussion}

Leiomyosarcoma commonly arises from smooth muscle cells of abdominal viscera, retroperitoneal space, soft tissue of the extremities and uterus. This condition is usually seen in women of perimenopausal ages. Adelani et al., (2009) found the median age affected to be 47 years, with a range from 9 to 87 years. In terms of tumor locality, there is a general consensus that long bones are primarily affected, predominantly the distal femur and proximal tibia with $45 \%$ and $26 \%$ of patients, respectively [16].

\section{Primary Leiomyosarcoma of the Spine}

Primary osseous leiomyosarcoma is rare, with the femur being the commonest bone to be affected. Up to 2017, there have only been 12 reported cases of primary leiomyosarcoma of the spine. The first case report was published by Lo et al. in 1995 with an eighth thoracic vertebral lesion, causing spinal cord compression. The most common site of the spine involvement was thoracic spine in 7 cases, followed by cervical spine 2 cases, lumbar spine 2 cases, and sacrum 2 cases. The symptoms are usually nonspecific, ranging from progressive pain, swelling, masses and to pathological fractures and potential neurological deficits secondary to spinal cord compression [17]. Up to 2021, our patient is the 13th case of primary leiomyosarcoma of the spine to be reported.

\section{Tumor Behaviour}

Generally, leiomyosarcoma is an aggressive tumor that is typically characterised by extensive infiltration, with metastasis developing in the first few years after initial diagnosis [17]. This is demonstrated here in our patient's tumor which infiltrated the spinal cord and bilateral nerve roots of both L2 and L3, accompanied by lung metastasis.

\section{Investigation}

Immunohistochemistry studies are the important investigation to confirm the diagnosis of leiomyosarcoma, especially in differentially diagnoses from other types of carcinomas. The typical microscopy features of leiomyosarcoma are of sharp, marginated fascicles of spindle cells that intersect and commonly stain positive for h-caldesmon, smooth muscle actin and desmin [18].

Following a detailed history taking, clinical and radiological investigations and immunohistochemical staining, the diagnosis of primary leiomyosarcoma in our patient is established after exclusion of metastatic leiomyosarcoma to the spine. Her low back pain, bilateral lower limb weaknesses and right leg paresthesia are commensurate with the CT and MRI findings of tumor involvement of the spinal cord and nerve roots, mainly at the L2 and L3 vertebral level. Her chest CT findings confirmed metastasis to the lung and a consult with thoracic surgical team has been arranged.

Histological examination by $\mathrm{H} \& \mathrm{E}$ alone is unable to differentiate the tissue of origin and the undifferentiated sarcomas. Therefore, immunohistochemical stains are vital in these cases to distinguish from other carcinomas. Immunohistochemical staining often shows that leiomyosarcoma is almost uniformly positive for both SMA and desmin, but negative for both keratins and S-100 protein.

The MRI and CT images would categorize our patient as a Type 5 extracompartmental para-verterbral tumor involvement in Tomita's surgical classification, amenable to a 2-stage Total en-bloc spondylectomy, which has been attempted for this patient. Intralesional resection of the tumor was performed in our patient due to tumor infiltration of the thecal sac, bilateral nerve roots and vertebral body involvement. This extensive involvement made total en-bloc resection impossible to execute.

\section{Treatment}

Surgery is the main treatment option that can relieve symptoms and improve the prognosis. Our patient's neurological status improved dramatically upon posterior decompression and stabilization of her spine.

Table 1 below illustrates that surgical resection, with or without postoperative radiation, was the main method of treatment for these other 12 patients reported in the literature whose survival time was commonly $>6$ months. One patient was treated by radiation only, 4 patients were treated by surgery only, and 4 patients were treated by both surgery and radiation. Embolization was used only in 2 patients as a supplementary measure. Our patient (13th to be reported in the world) had both surgery(S) and adjuvant radiotherapy (R). 
Table 1: 13 Cases of primary osseous leiomyosarcoma reported from 1995 to 2020.

\begin{tabular}{|c|c|c|c|c|c|c|c|c|c|}
\hline No & Author & Year & Age & Sex & Presenting complaint & Site & $\begin{array}{l}\text { Compression } \\
\text { fracture }\end{array}$ & $\begin{array}{l}\text { Initial } \\
\text { treatment }\end{array}$ & Outcome \\
\hline 1 & Lo et al. & 1995 & 39 & M & Loss of sensation & $\mathrm{T} 8$ & No & $S$ & NED \\
\hline 2 & Antonescus et al. & 1997 & 36 & $M$ & N/A & L2 & N/A & $\mathrm{S}$ and $\mathrm{R}$ & $\begin{array}{l}\text { DOD } 6 \text { months with METS } \\
\text { (lung) }\end{array}$ \\
\hline 3 & Ochiai et al. & 2000 & 69 & M & $\begin{array}{l}\text { Neck pain and numbness of } \\
\text { hands }\end{array}$ & $\mathrm{C} 7$ & Yes & $\mathrm{R}$ & $\begin{array}{l}\text { DOD } 6 \text { months with METS } \\
\text { (intraspinal, pleural and } \\
\text { liver) }\end{array}$ \\
\hline 4 & Ritter et al. & 2000 & 35 & $\mathrm{~F}$ & Weakness of lower extremities & T3-4 & N/A & $\mathrm{S}$ and $\mathrm{R}$ & N/A \\
\hline 5 & Nishida et al. & 2002 & 47 & $\mathrm{~F}$ & Low back pain & L2 & N/A & $\mathrm{R}$ and $\mathrm{S}$ & NED 2 years 1 month \\
\hline 6 & Sasaguri et al. & 2004 & 75 & $\mathrm{~F}$ & Lumbago & $\mathrm{T} 12$ & Yes & $\mathrm{S}$ & NED 4 months \\
\hline 7 & Dohi et al. & 2003 & 67 & $\mathrm{~F}$ & Left buttock pain & Sacrum & No & S and $\mathrm{R}$ & DOD cachexia 2 years later \\
\hline 8 & Ganau et al. & 2002 & 23 & $\mathrm{~F}$ & $\begin{array}{l}\text { Pain in the right sacroiliac } \\
\text { region }\end{array}$ & Sacrum & No & $\begin{array}{l}\text { Embolisation, } \\
\mathrm{S} \text { and R }\end{array}$ & N/A \\
\hline 9 & Potsi et al. & 2012 & 57 & F & $\begin{array}{l}\text { Low back pain and leg } \\
\text { weakness }\end{array}$ & T11 & No & S & NED 6-months follow-up \\
\hline 10 & Sucu et al. & 2011 & 25 & $F$ & $\begin{array}{l}\text { Pain in the cervical region and } \\
\text { left upper extremity }\end{array}$ & $\mathrm{C} 2$ & No & $S$ & NED 15-months follow-up \\
\hline 11 & Tahara et al. & 2016 & 61 & $F$ & Back pain & T9 & No & $\begin{array}{l}\mathrm{S} \text { and } \\
\text { embolisation }\end{array}$ & NED 6-months follow-up \\
\hline 12 & Yang et al. & 2016 & 47 & $\mathrm{~F}$ & Back pain & T11 & No & $S$ & NED 6-months follow-up \\
\hline 13 & $\begin{array}{l}\text { PGH/RUMC } \\
\text { group }\end{array}$ & 2020 & 56 & $\mathrm{~F}$ & $\begin{array}{l}\text { Low back pain and bilateral } \\
\text { lower limb weakness }\end{array}$ & L3 & Yes & $S$ & On follow-up \\
\hline
\end{tabular}

\section{Primary Osseous Leiomyosarcoma Clinicopathologic and Prognostic Factors, Survival Rates According to Histological Subtypes, Grading \& Staging}

The overall prognosis was poor. After the diagnosis was made, two cases had died 6 months later due to metastasis, 1 case had died 2 years later due to cachexia, 2 cases were loss follow up, and 8 cases are still being followed up (6 months to 2 years follow-up) [19].

Based on a retrospective review of data stored on a prospective database, all patient disease-specific survival (DSS) was $57 \%$ at five years and $44 \%$ at ten years but for those without metastases was $82 \%$ and $60 \%$. The only factor associated with statistically significant improved survival was the absence of metastases at diagnosis [20].

From the Gladdy et al. report in 2013, the significant independent predictors of DSS were high grade and size. Significant independent predictors for local recurrence (LR) were size, margin, multiple surgical procedures (MSP) and distant metastases (DM). Positive microscopically margins with DM had 3.73 times a higher risk of LR than negative microscopically margins. Patients with MSP had 21.06 times a higher risk of LR than patients that had a single procedure. Patients with DM had 8.34 times a higher risk of LR than patients without metastasis. Predictors for DM were size and grade of tumor, commonly involving distant recurrence in the lung. The overall survival rate in 5 years: influenced by FNLCC, LR, MSP, DM [21].

\section{Conclusion}

Accurate diagnosis of spinal leiomyosarcoma can be made using correct imaging modalities, tissue biopsy and immunohistochemical stains against the various antibodies against the epithelial and mesenchymal cell markers, despite the rarity of spinal leiomyosarcoma. Surgical resection, with or without adjuvant radiotherapy, remains the main choice of treatment.

\section{Consent}

Patient has given consent for publication of her case report and use of medical data/ information.

\section{Data Availability}

No additional data is available.

\section{Conflicts of Interest}

None.

\section{Funding}

None.

\section{REFERENCES}

1. Nanassis K, Rudolf CA, Tsitsopoulos P (1999) Spinal manifestation of metastasizing leiomayosarcoma. Spine 24: 987-989. [Crossref]

2. Russell WO, Cohen J, Enzinger F, Hajdu SI, Heise H et al. (1977) A clinical and pathological staging system for soft tissue sarcomas. Cancer 40: 1562-1570. [Crossref]

3. Ziewacz JE, Lau D, Marca FL, Park P (2012) Outcomes after surgery for spinal metastatic leiomyosarcoma. J Neurosurg Spine 17: 432-437. [Crossref] 
4. Evans DM, Sanerkin NG (1965) Primary leiomyosarcoma of bone. $J$ Pathol Bacteriol 90: 348-350. [Crossref]

5. Kameda N, Kagesawa M, Hiruta N, Akima M, Ohki M et al. (1987) Primary leiomyosarcoma of bone. A case report and review of the literature. Acta Pathol Jpn 37: 291-303. [Crossref]

6. Sassi SH, Khattech R, Dhouib R, Rameh S, Mrad K et al. (1999) Primary bone leiomyosarcoma. Anatomo-clinical, immunohistochemical, and ultrastructural study. Rev Chir Orthop Reparatrice Appar Mot 85: 865-870. [Crossref]

7. Bouaziz MC, Chaabane S, Mrad K, Oueslati S, Bellassoued A et al. (2005) Primary leiomyosarcoma of bone: report of 4 cases. J Comput Assist Tomogr 29: 254-259. [Crossref]

8. Miura K, Hatori M, Hosaka M, Kokubun S, Watanabe M et al. (2001) Primary leiomyosarcoma with the invasion into intertrabecular space of bone: a case report. Clin Imaging 25: 209-214. [Crossref]

9. Klimo P Jr, Schmidt MH (2004) Surgical Management of Spinal Metastases. Oncologist 9: 188-196. [Crossref]

10. Stener B (1971) Total spondylectomy in chondrosarcoma arising from the seventh thoracic vertebra. J Bone Joint Surg Br 53: 288-295. [Crossref]

11. Tomita K, Kawahara N, Baba H, Tsuchiya H, Nagata S et al. (1994) Total en bloc spondylectomy for solitary spinal metastases. Int Orthop 18: 291-298. [Crossref]

12. Tomita K, Kawahara N, Murakami H, Demura S (2006) Total En Bloc Spondylectomy for Spinal Tumors: Improvement of the Technique and Its Associated Basic Background. J Orthop Sci 11: 3-12. [Crossref]

13. Tomita K, Kawahara N, Baba H, Tsuchiya H, Fujita T et al. (1997) Total en bloc spondylectomy. A new surgical technique for malignant vertebral tumors. Spine 22: 324-333. [Crossref]
14. Tomita K, Kawahara N, Murakami H (2016) Primary and Metastatic Tumors of the Spine: Total En Bloc Spondylectomy. Operative Techniques in Orthopaedic Surgical Oncology. Springer 2016: 1-9.

15. Chanplakorn $\mathrm{P}$, Chanplakorn $\mathrm{N}$, Pongtippan A, Jaovisidha $\mathrm{S}$, Laohacharoensombat W et al. (2011) Recurrent epithelioid sarcoma in the thoracic spine successfully treated with multilevel total en bloc spondylectomy. Eur Spine J 20: S302-S308. [Crossref]

16. Brewer P, Sumathi V, Grimer RJ, Carter SR, Tillman RM et al. (2012) Primary Leiomyosarcoma of Bone: Analysis of Prognosis. Sarcoma 2012: 636849. [Crossref]

17. Recine F, Bongiovanni A, Casadei R, Pieri F, Riva N et al. (2017) Primary leiomyosarcoma of the bone: a case report and a review of the literature. Medicine 96: e8545. [Crossref]

18. Cann TV, Cornillie J, Wozniak A, Rychter MD, Sciot R et al. (2018) Retrospective Analysis of Outcome of Patients with Metastatic Leiomyosarcoma in a Tertiary Referral Center. Oncol Res Treat 41: 206-213. [Crossref]

19. Zumárraga JP, Arouca MM, Baptista AM, Caiero MT, Rubio DE et al. (2019) Primary Leiomyosarcoma Of Bone: Clinicopathologic And Prognostic Factors Analysis In A Single Institution. Acta Ortopédica Brasileira 27: 152-155. [Crossref]

20. Pluemvitayaporn T, Piyaskulkaew C, Kunakornsawat S, Pruttikul P (2017) Primary leiomyosarcoma of the spine treated with total en bloc spondylectomy: the first case in Thailand-a case report and literature review. J Spine Surg 3: 707-714. [Crossref]

21. Gladdy RA, Qin LX, Moraco N, Agaram NP, Brennan MF et al. (2013) Predictors of Survival and Recurrence in Primary Leiomyosarcoma. Ann Surg Oncol 20: 1851-1857. [Crossref] 